\title{
Entrevistas com a Profa. Dra. Maria Aparecida Santilli e o Prof. Dr. Benjamin Abdala Júnior
}

\author{
Por Alexandre Gomes da Silva, \\ Débora Leite David e \\ Érica Antunes
}

\section{Santilli: entre gestos pioneiros e atrevidos}

As afinidades entre os países de língua portuguesa existem e são compartilhadas desde há muito tempo, haja vista a circularidade decorrente das atividades colonialistas portuguesas a partir do final do século XV. Apesar desta ligação de séculos percebemos que foi a partir das lutas de libertação na "África Portuguesa" que passou a haver no Brasil um interesse crescente pelas literaturas africanas de língua portuguesa. Essa motivação iniciada em meio às dificuldades inerentes a um tempo de guerra e violência não se dobrou a nenhum obstáculo. Houve sim, um crescimento constante, numa progressão geométrica, com um número cada vez maior de estudantes, pesquisadores e professores dedicados ao assunto. Quando compulsamos os trabalhos acadêmicos desde então, deparamo-nos com a presença constante e pioneira da Professora Doutora Maria Aparecida Santilli. Atualmente professora de pós-graduação da Área de Estudos Comparados de Literaturas de Língua Portuguesa da Faculdade de Letras da Universidade de São Paulo, tem publicados títulos imprescindíveis ao estudo das literaturas de língua portuguesa, em que se destacam belíssimas análises sobre a obra de escritores dos países de língua portuguesa, notadamente de Angola, Moçambique, Portugal e do Brasil. Destas publicações não podemos deixar de mencionarEstórias africanas: história e antologia e Africanidades, publicados pela Editora Ática na década de 1980, e Paralelas e tangentes, publicado pela Editora Arte \& Ciência em 2003. Como nos conta o Professor Benjamin Abdala Júnior em seu texto de abertura Abrindo caminhos, livro de homenagem à professora que reuniu textos oferecidos por seus colegas, amigos e alunos, Maria Aparecida Santilli foi a autora de um gesto "atrevido" e pioneiro ao promover a abertura de uma nova área de estudos: a disciplina de Literaturas Africanas de Língua Portuguesa. Uma atitude inovadora e audaz, haja vista que a Universidade de São Paulo foi a primeira a ter a mencionada disciplina, isso ainda em tempos revoltos e atribulados de ditadura no Brasil.

Revista Crioula - Como a senhora vê o surgimento e atuação, hoje, da Comunidade dos Países de Língua Portuguesa?

Maria Aparecida Santilli - Vejo favoravelmente, num universo hoje configurado em blocos de países organizados em função de afinidades, ou metas comuns.

Revista Crioula - A senhora é a favor ou contra a padronização da Língua Portuguesa nos três continentes?

Maria Aparecida Santilli - Não diria padronização, mas sim estabelecimento de possíveis normas comuns que facilitariam o entendimento de usuários de outras línguas.

Revista Crioula- Gostaríamos que nos contasse um pouco sobre a raiz do seu trabalho dedicado às literaturas africanas de língua portuguesa. Quando começou? Havia dificuldades? Quais? Como as venceu? Como fazia para conseguir livros e fortuna crítica destes escritores africanos de língua portuguesa?

Maria Aparecida Santilli - Por ocasião de bolsas de pós-doutorado que tive, em Portugal (1968 e 1971), conheci escritores neo-realistas portugueses sobre cuja obra estava pesquisando. Desse relacionamento com eles, leitores e admiradores de escritores africanos que 
eram, surgiu o embalo inicial para recolher o que era possível encontrar de livros africanos e de informações disponíveis sobre essas literaturas, então emergentes. Foi um período difícil. A chamada "África Portuguesa" estava em luta de libertação política, com escritores presos e inibidos de publicarem o que escreviam ou poderiam escrever. Tudo isso me levou a diferentes tentativas de resolver essa dificuldade de acesso. São gratificantes para mim as lembranças de tantos gestos de boa-vontade, para que eu vencesse esse tipo de obstáculo. Recordo-me, por exemplo, dessa primeira fase, que conheci Paulo Freire exilado. Trabalhava no Conselho Mundial das Igrejas, em Genebra, onde fui visitar outro exilado brasileiro, Lisâneas Maciel, que trabalhava no mesmo organismo internacional. Lá me encontrei com o colega da USP Francisco Weffort, genro de Paulo Freire, que o acompanhava e a ele me apresentou como "nova estudiosa das Literaturas Africanas de Língua Portuguesa". Paulo Freire havia chegado recentemente da África e prontificou-se me mandar, depois, para o Brasil, vários livros que lá ganhara. E mandou... É fácil imaginar a minha gratidão...

Revista Crioula- Como foi a sua primeira viagem à África?

Maria Aparecida Santilli - Foi a convite do Ministério da Cultura de Angola e da União de Escritores Angolanos. O Ministério convidou-me para seminários de ensino do Português como segunda língua e de Literatura, que se realizaram no Lubango. Lembro-me das surpresas que tive e do quanto aprendi nas oficinas aí efetuadas. Eram professores muito jovens, vindos de diversas partes do país, nas quais a diversidade das respectivas línguas maternas ditava como pertinente e urgente trocar experiências nessa área. Ligaram-me a um dos vários grupos de discussão e de planejamento de estratégias de ensino. Nunca me esquecerei da primeira aula dada por um dos membros do meu grupo, que simulou o papel de alunos de uma hipotética classe, de como todos "representaram", como se crianças efetivamente fossem, e quanto rimos do espetáculo lúdico que foi... Como eu era a única estrangeira, todos os grupos pediam minha opinião sobre seu desempenho. A União convidou-me para uma palestra que transcorreu em ambiente muito descontraído e afável, onde conheci vários escritores, e de onde se originaram outros convites e conhecimentos preciosos. Quem me acompanhava era o escritor Antônio Cardoso, então secretário da União. Desse primeiro contato, guardo fotografias com Luandino Vieira...

Revista Crioula- Quais as dificuldades ao se considerar criticamente autores que, embora escrevam em língua portuguesa, estão imersos em contextos sócio-culturais distintos?

Maria Aparecida Santilli - Antes de mais nada, somos um povo habituado à prática de convivência com a diferença. Somos um povo crioulo. Depois, creio que operar criticamente com autores de diferentes contextos sócio-culturais, ainda que escrevam na mesma língua, é um desafio, é sedutor, pelo próprio fato de eles, partindo de um instrumento em princípio comum, exercitarem fórmulas de criar a diversidade de expressão em que se manifestam suas respectivas peculiaridades.

Revista Crioula - Em que medida a compreensão da interação social e política existente entre os diversos países lusófonos pode auxiliar os Estudos Comparados de Literaturas de Língua Portuguesa?

Maria Aparecida Santilli - A interação social e política entre os diversos países lusófonos poderá ser incentivadora de estudos comparados de literaturas de língua portuguesa, como será estimuladora de ações culturais articuladas, do entendimento de afinidades, de recíproca compreensão das culturas e do respeito pelas diferenças.

Revista Crioula- Deixe-nos recomendações de leituras para alunos que estão se iniciando nesta área.

Maria Aparecida Santilli - Essa é uma tarefa difícil...redutível...falível, sobretudo numa circunstância isolada como esta, de rápida entrevista. Nos cursos costumo indicar uma lista 
bibliográfica básica. Mas vou acrescentando obras específicas, recomendáveis para cada tópico desenvolvido.

\section{Dos gestos pioneiros à consolidação de perspectivas radicais}

Atualmente, a área de Estudos Comparados de Literaturas de Língua Portuguesa encontra no Professor Doutor Benjamin Abdala Júnior um dos seus expoentes e grandes defensores. Suas reflexões e perspectivas teóricas têm garantido fôlego à área bem como ao comparatismo na Universidade de São Paulo. Entre suas obras mais recentes, devem ser citadas Fronteiras Múltiplas: identidades plurais, um ensaio sobre mestiçagem e hibridismo cultural (2002) e De vôos e ilhas: literatura e comunitarismos(2003). Entre as organizações mais recentes temos, Portos flutuantes: trânsitos ibero-afro-americanos(2004) e Moderno de nascença: figurações críticas do Brasil (2006).

Revista Crioula - Como surgiu a área de Estudos Comparados de Literaturas de Língua Portuguesa da Universidade de São Paulo? Tomou-se como modelo alguma área similar em outra universidade? Enfim, o que norteou sua concepção e como esta ganhou materialidade?

Benjamin Abdala Júnior - A área surgiu de um grupo de professores que desenvolviam um projeto articulado entre as produções literárias do Brasil e Portugal, em quatro recortes: a geração portuguesa de 70 e o Brasil (Elza Miné); o Modernismo no Brasil e Portugal (Nádia Battella Gotlib); o neo-realismo no Brasil e em Portugal (Maria Aparecida Santilli) e relações culturais Brasil/Portugal após a Revolução de Abril (Benjamin Abdala Junior). Articulavam-se, dessa forma, projetos que se iniciaram antes, a maioria inclusive, em projetos de pósgraduação. Quando comecei meu mestrado, em 1971, eu já seguia uma perspectiva comparada nos estudos sobre Graciliano Ramos e Carlos de Oliveira. Para mim já estava claro que seria mais importante para nós brasileiros estudarmos a Literatura Portuguesa a partir de nossa perspectiva. Isto é, com os pés no Brasil - perspectiva que releva o comparatismo. Os portugueses poderiam melhor estudá-la centrando-a de forma mais enfática no país de origem. Tratei desse assunto no congresso da Associação Brasileira dos Professores Universitários de Literatura Portuguesa realizado em Belo horizonte, na UFMG, e, ele provocou vivo debate, mostrando já um divisor de área entre professores mais tradicionais e aqueles que queriam dinamizar o ensino e pesquisa dessa área (que felizmente era a maioria e a proposta contava inclusive com apoio de professores mais velhos). Na altura, eu defendia também a idéia de que essa literatura fosse ensinada numa perspectiva brasileira e contemporânea, de forma a mostrar como as formas da tradição repercutiam na atualidade. O importante seria impactar o aluno com o melhor da Literatura Portuguesa, mostrando como esses textos se relacionam com problemas e questões vivenciados pelo aluno brasileiro. Como se observa, nossa proposta de área de pesquisa teve origem na prática que estávamos desenvolvendo, um campo de pesquisa que já existia de forma efetiva e que precisava ser nomeado, tendo em vista aproximar novos docentes e alargar os projetos dentro das normas dos cursos de pós-graduação. Esta é uma área nova, no Brasil e no Exterior. Uma área, entendo, que procura responder à necessidade de redefinição das disciplinas de Letras. Os recortes tradicionais, como sabemos, estão superados. Sem interdisciplinaridade, não há conhecimento novo. É necessário que a universidade (e isso vale para todos os campos do conhecimento) se afaste das compartimentações do passado, que hoje só existem para justificar mini-privilégios de caráter corporativo. Por outro lado, há um sentido político na criação desse programa de pesquisa. Em face do atual processo de mundialização, que impõe a estandardização dos produtos culturais, marcada por quem tem hegemonia, tornase importante mostrar a nossa diferença, a nossa maneira de ser. Identidade não é algo estabelecido e de sentido passadiço, pois pressupõe atualização/transformação. Uma comunidade que se renova, sem se descaracterizar. Pois bem, num mundo onde o inglês é língua franca, é importante falar também em português. E com a comunidade da língua 
articulam-se as culturas que a envolvem. Logo, para se fazer face à mundialização descaracterizadora, é necessário relevar nosso comunitarismo cultural. E comparar é uma forma de nos estudarmos em nossas semelhanças e também em nossas diferenças. Se há raízes comuns que permitem a realização de estudos comparados, estes interessam-nos sobretudo para que nossos povos continuem a caminhar na mesma direção. $O$ que nos atrai é o futuro.

Revista Crioula - Podemos dizer que os Estudos Comparados de Literaturas de Língua Portuguesa (ECLLP) constituem, na verdade, uma subárea da Literatura Comparada, ou quando falamos em Estudos Comparados estamos nos referindo a um objeto mais amplo que o da Literatura Comparada?

Benjamin Abdala Júnior - Os ECLLP seguem as perspectivas do comparatismo literário atual (horizontes interdisciplinares e intersemióticos). Não se limita, pois, ao comparatismo binário do passado, que desconsiderava a articulações entre literatura e as outras séries da cultura. Nesses estudos, o corpus básico é literário, entendido como intersecção/tradução dessas séries. Não podemos desconsiderar, para uma análise mais aprofundada do texto literário, do contributo que vem da história, da filosofia, da antropologia etc. E também de outras artes. Há, entretanto, um recorte: o estudo entre produções literárias de mais de um país de língua oficial portuguesa. Trata-se, pois, de estudos críticos. É evidente que não há bom estudo crítico sem suporte numa conveniente teoria da literatura comparada. Esta deve estar sempre em nosso horizonte. Talvez no futuro se possa constituir em ECLLP uma linha de pesquisa voltada para essa teorização no específico de nossas articulações comunitárias, mas o enfoque atual é de estudos críticos (que de alguma forma incorpora na práxis a teoria e contribui para seu desenvolvimento).

Revista Crioula - Tendo em vista que a área envolve o estudo da literatura e da cultura de sete países (Portugal, Brasil, Angola, Moçambique, Cabo Verde, Guiné-Bissau e São Tomé e Príncipe) situados em três continentes (Europa, América e África), qual é o grau de internacionalização pretendido, isto é, há alguma intenção de se estreitar relações entre os estudiosos de pontos tão distantes no globo? Quais seriam as estratégias empregadas para tanto?

Benjamin Abdala Júnior - É necessário que venhamos a incluir ainda a literatura do imigrante, do Timor Leste, de Macau, de Goa. A internacionalização pretendida vem das articulações comunitárias que sonhamos desenvolver. A cooperação internacional, nesse sentido, é fundamental. Já firmamos convênios com várias universidades de língua portuguesa. Precisamos agora é de recursos para que eles não sejam letra morta e possam favorecer ações sistemáticas. Parece-me evidente que essas ações não devam se circunscrever ao campo das letras, mas constituir formas de cooperação interuniversitárias mais amplas, alargando-as para outras áreas do conhecimento. Nesse sentido, está sendo dinamizada a Associação das Universidades de Língua Portuguesa (AULP) e também a presença da USP nessa instituição. Não se pode descartar (ao contrário, é necessário desenvolver) o papel da Comunidade dos Países de Língua Portuguesa (CPLP) nesses convênios. A CPLP poderia articular as esferas de governo e a AULP poderia interferir para que essa entidade fosse mais que uma sigla. 